\title{
Cemaran Mikroba pada Bubuk Temu Putih (Curcuma zedoaria (Berg) Roscoe) dalam Kantung Teh Celup selama Penyimpanan Suhu Ruang
}

\section{Microbial Contamination on (Curcuma zedoaria (Berg) Roscoe) Powder in Tea Bag during Room Temperature Storage}

\author{
Amelia Rovina $^{1}$, Luh Putu Trisna Darmayanti ${ }^{{ }^{*}}$, Agus Selamet Duniaji ${ }^{1}$ \\ Program Studi Teknologi Pangan, Fakultas Teknologi Pertanian, Universitas Udayana \\ Kampus Bukit Jimbaran, Badung-Bali \\ *Penulis korespondensi: Luh Putu Trisna Darmayanti, Email: trisnadarmayanti@unud.acid
}

\begin{abstract}
The zedoary rizome (Curcuma Zedoaria (Berg) Roscoe) has a curcumin compound, which is one of the active compounds in the rhizome. Fresh zedoary rizome is easily damaged so it is often preserved by drying it. This research was aimed to determine the microbial contamination of the zedoary rizome packed in tea bags during storage in a room temperature. This research used Completely Randomized Design with storage at room temperature as a treatments, which consisted of 5 levels: 0 days, 7 days, 14 days, 21 days and 28 days. With 3 replication to obtain 15 units of sample. Data were analyzed by Analysis of Variance (ANOVA) and followed by multiple comparison test of Duncan Multiple Range Test (DMRT). The result showed that during storage, there were carasteristics changes in zedoary rizome powder such as increased of total plate count, total mold and yeast count, coliform and water content, but there was no E. coli growth. The zedoary rizome powder in tea bags during storage on days 0 to 28 fulfilled the requirements for food safety because microbial growth is below the maximum limit of Indonesian National Standard (SNI), but the water content on days 14 to 28 does not meet the SNI requirements.
\end{abstract}

Keywords: microbial contamination, tea bag, zedoary rizome

\section{PENDAHULUAN}

Tanaman Zingiberaceae atau disebut juga kelompok temu-temuan secara umum digunakan sebagai bumbu dapur, pengawet makanan, pewarna makanan alami, bahan masakan dan juga digunakan sebagai obat alternatif di beberapa negara, khususnya di wilayah Asia (Rahman et al., 2013). Tanaman temu putih (Curcuma zedoaria (Berg) Roscoe) yang disebut juga white turmeric merupakan tanaman herbal famili Zingiberaceae yang ditemukan di negara-negara tropis seperti Indonesia, India, Jepang dan Thailand (Lobo et al., 2009). Temu putih memiliki senyawa kimia seperti alkaloid, fenolik, flavonoid, saponin, glikosid, steroid dan terpenoid (Sumathi et al., 2013). Kurkumin merupakan salah satu senyawa aktif pada rimpang temu putih yang merupakan senyawa turunan fenolik (polifenol) yang termasuk ke dalam kelompok kurkuminoid, senyawa kurkumin ini berkhasiat sebagai antikanker (Chen dan Tan, 1998). Temu putih memiliki rasa pahit dan hangat saat dikonsumsi.

Temu putih segar mudah rusak sehingga sering diawetkan dengan cara dikeringkan. Rentang waktu antara produksi dengan pemakaian produk dapat mengakibatkan produk mengalami penurunan mutu dan kerusakan. Pengemasan dapat menekan kerusakan komoditi selama waktu tertentu. Umur simpan perlu diketahui agar komoditi termasuk temu putih kering bubuk dapat digunakan pada kondisi mutu optimalnya. Menurut Yuliasih et al., 2006 bubuk kering jahe merah yang 
disimpan pada suhu $30^{\circ} \mathrm{C}$ mempunyai umur simpan selama 544 hari.

Pemanfaatan temu putih yang dikonsumsi masyarakat umumnya hanya dalam bentuk serbuk, maupun sebagai bahan tambahan makanan, sehingga dinilai kurang maksimal. Salah satu cara untuk meningkatkan pemanfaatan temu putih yaitu diolah menjadi teh herbal. Namun jika dalam bentuk serbuk pada saat diseduh akan menghasilkan endapan. Saat ini secara perlahan terjadi perubahan pola konsumsi masyarakat dari teh seduh ke teh celup. Teh celup merupakan produk olahan teh yang dikemas di dalam kemasan kantung (bag) yang terbuat dari filter paper (Handayani, 2010). Beralihnya konsumen dari teh seduh ke teh celup sejalan dengan perubahan gaya hidup masyarakat yang semakin menginginkan kepraktisan, termasuk dalam menyeduh teh.

Salah satu faktor penting yang mempengaruhi mutu bubuk temu putih adalah kemasan dan penyimpanan. Kemasan bubuk untuk minuman herbal yang umum dipergunakan yaitu kantung teh celup. Selama penyimpanan ada kemungkinan terjadi kerusakan pada bubuk temu putih, sehingga bubuk tidak lagi memenuhi persyaratan yang diperlukan. Pada rumah tangga penyimpanan yang umum dilakukan yaitu teh disimpan pada suhu ruang dan dibiarkan terbuka. Produk bubuk temu putih diduga dapat mengalami kerusakan pangan yaitu kerusaakan mikroiologis, kerusakan ini disebabkan oleh mikroorgansime seperti kapang, bakteri dan khamir(ragi). Bakteri pada umumnya mudah merusak bahan bahan yang mengandung kadar air tinggi. Air dalam substrat yang digunakan untuk pertumbuhan mikroba biasanya dinyatakan dengan istilah water activity (aw).Sedangkan kapang membutuhkan aw yang lebih sedikit dibanding khamir dan bakteri. Bahan pangan kering dapat menghasilkan air, misalnya jika suhu naik selama pengepakan, mengakibatkan kelembaban nisbi pada permukaan akan berubah. Uap air ini kemudian dapat berkondensasi pada permukaan bahan pangan, sehingga menyebabkan terjadinya pertumbuhan mikroorganisme.

Pengujian cemaran mikroba dalam sediaan bahan pangan meliputi total mikroba, uji kapang/ khamir (AKK), serta uji Most Probably Number (MPN) untuk menguji adanya bakteri koliform dan uji cemaran mikroba patogen seperti Escherichia coli, Salmonella sp, Pseudomonas aeuroginosa, Staphylococcus aureus dan mikroba patogen lain (Pratiwi, 2008). Menurut Anonim tahun 1990 batas kontaminan mikroba pada sediaan minuman herbal asal tanaman yaitu angka cemaran bakteri < $10^{4}$ per gram, angka kapang dan khamir $<10^{2}$ per gram, negatif untuk angka Most Probablity Number (MPN) dan mikroba patogen. Dari latar belakang diatas, penelitian ini dilakukan dengan tujuan untuk mengetahui cemaran mikroba pada bubuk temu putih yang dikemas dalam kantung teh celup selama penyimpanan suhu ruang dan mengetahui berapa lama bubuk temu putih dalam kantung teh celup masih memenuhi syarat aman untuk dikonsumsi.

\section{METODE PENELITIAN}

\section{Tempat dan Waktu}

Penelitian ini dilaksanakan di Laboratorium Pengolahan Pangan, Laboratorium Mikrobiologi Pangan dan Laboratorium Analisis 
Pangan Program Studi Teknologi Pangan, Fakultas Teknologi Pertanian, Universitas Udayana. Pelaksanaan penelitian ini dilakukan pada bulan Januari 2020 sampai dengan bulan Maret 2020.

\section{Bahan dan Alat}

Alat - alat yang digunakan dalam penelitian ini adalah pisau, talenan, baskom, tampah, loyang, blender, ayakan 40 mesh, plastik, sendok, oven, timbangan analitik, botol kaca, batang bengkok, mikropipet, inkubator (Memmert), tip, laminar flow cabinet (Kojair), bunsen, kertas label, vortex, korek api, mikroskop, cawan petri plastik, tabung reaksi (Pyrex), rak tabung (Pyrex), gelas beker (Pyrex), kulkas, dan labu ukur.

Bahan yang digunakan dalam penelitian ini adalah rimpang temu putih (Curcuma zedoaria (Berg) Roscoe) dengan umur panen \pm 9 bulan, tea bag, quades steril, buffer peptone, lactose broth, media Plate Count Agar (PCA) (Merck), media Potato dextrose-agar (PDA) (Merck), media Eosin Methylene Blue Agar (EMBA) (Oxoid), alkohol $95 \%, 70 \%$ alumunium foil dan tisu.

\section{Rancangan Penelitian}

Rancangan percobaan yang digunakan pada penelitian ini adalah Rancangan Acak Lengkap (RAL) dengan faktor perlakuan lama penyimpanan pada suhu ruang. Lama penyimpanan pada suhu ruang bubuk temu putih dalam kantung teh celup dengan 5 taraf perlakuan yaitu 0 hari, 7 hari, 14 hari, 21 hari dan 28 hari. Masing-masing perlakuan diulang sebanyak 3 kali sehingga diperoleh 15 unit percobaan. Data yang diperoleh kemudian dianalisis dengan analisis ragam dan apabila terdapat pengaruh antara perlakuan dilanjutkan dengan Uji Jarak Berganda Duncan (Gomez dan Gomez, 1995).

\section{Pelaksanaan Penelitian}

\section{Pembuatan Sampel}

Pembutan bubuk rimpang temu putih diawali dengan pengambilan rimpang temu putih segar. Setelah itu, rimpang temu putih dibersihkan dari kotoran yang menempel dengan air mengalir lalu ditiriskan, rimpang temu putih lalu dikupas dan dicuci kembali. Kemudian rimpang temu putih diiris $\pm(1 \mathrm{~cm})$ dan dikeringkan menggunakan oven dengan suhu $50^{\circ} \mathrm{C}$ selama 24 jam atau dengan kriteria mudah di patahkan. Rimpang temu putih yang telah kering kemudian di blender dan diayak dengan ayakan 40 mesh hingga didapatkan bubuk rimpang temu putih. Masing-masing bubuk temu putih kemudian ditimbang sebanyak 2 gram lalu dimasukan kedalam kantung teh celup.

\section{Variabel yang Diamati}

Variabel penelitian yang diamati yaitu Kadar Air (Sudarmaji,1997), Total mikroba dan Angka Kapang Khamir (AKK) (Buckle, 1987), Koliform dan Escherichia coli (Cappucino dan Sherman, 1992) sesuai SNI 3836:2013.

\section{HASIL DAN PEMBAHASAN}

\section{Kadar Air}

Hasil analisis ragam menunjukkan bahwa lama penyimpanan berpengaruh sangat nyata $(p<0,01)$ terhadap total kadar air bubuk temu putih dalam kantung teh celup dapat dilihat pada Tabel 1. 
Tabel 1. Hasil uji kadar air bubuk temu putih dalam kantung teh celup selama penyimpanan suhu ruang

\begin{tabular}{cccc}
\hline Sampel & Kadar Air (\%) & $\begin{array}{c}\text { Standard SNI } \\
3836: 2013\end{array}$ & Keterangan \\
\hline 0 & $2,56 \pm 1,36$ a & & Memenuhi syarat \\
7 & $6,76 \pm 1,58 \quad$ b & $8 \%$ & Memenuhi syarat \\
14 & $12,42 \pm 1,97 \mathrm{c}$ & Tidak Memenuhi syarat \\
21 & $24,48 \pm 1,58 \mathrm{~d}$ & Tidak Memenuhi syarat \\
28 & $31,87 \pm 1,41 \mathrm{e}$ & Tidak Memenuhi syarat \\
\hline Keterangan: Huruf yang sama dibelakang nilai rata-rata pada kolom yang sama menunjukkan nilai rata-rata tidak berbeda \\
nyata $(\mathrm{P}>0,05)$
\end{tabular}

Nilai rata- rata kadar air bubuk temu putih dalam kantung teh celup dapat dilihat pada Tabel 1. Pada hari ke-0 hingga hari ke7 kadar air masih memenuhi syarat yaitu $2,56 \%$ dan $6,76 \%$, sedangkan pada hari ke-14 hingga hari ke-28 kadar air terus meningkat diatas batas maksimal syarat SNI 3836:2013. Menurut penelitian Shahzadi et al., 2005, peningkatan kadar air disebabkan penyerapan uap air dari lingkungan untuk mencapai kondisi kesetimbangan. Adanya perbedaan kelembaban antara lingkungan dengan sampel minuman serbuk akan menyebabkan perbedaan tekanan parsial uap air. Perbedaan tekanan parsial uap air menyebabkan perpindahan uap air dari daerah yang bertekanan tinggi ke daerah bertekanan rendah. Karena tekanan parsial atau kelembaban uap air lingkungan lebih besar dari tekanan parsial uap air sampel dalam kemasan, maka uap air akan berpindah ke dalam sampel tersebut. Dalam penelitian ini, peningkatan kadar air diduga disebabkan mudahnya bubuk menyerap air pada ruangan terbuka. Penyimpanan terbuka tersebut yang menyebabkan penyerapan air semakin meningkat. Kantong teh yang memiliki rongga-rongga yang cukup besar semakin mempermudah air mudah terserap dan semakin hari kadar air akan meningkat (Rahayu dan setiowati, 2010).

Adanya aktivitas mikrobia yang tumbuh juga dapat menyebabkan perubahan kadar air pada produk pangan. Mikrobia menghasilkan $\mathrm{H}_{2} \mathrm{O}$ atau uap air sebagai salah satu produk metabolisme (Sopandi, 2014). Metabolisme adalah proses kimiawi yang terjadi di dalam sel hidup untuk kelangsungan hidup sel (Radji, 2011). Mikroorganisme aeorb serta beberapa fakultatif anaerob dalam kondisi aerob dapat menggunakan molekul oksigen sebagai penerima elektron akhir selama metabolisme karbohidrat, untuk menghasilkan piruvat melalui satu jalur utama metabolisme.Piruvat yang dihasilkan dapat dioksidasi secara lengkap melalui dekarboksilasi oksidasi untuk menghasilkan $\mathrm{CO}_{2}, \mathrm{H}_{2} \mathrm{O}$ dan sejumlah ATP (Adenosine Trifosfat).

\section{Total Mikroba}

Hasil analisis ragam menunjukkan bahwa lama simpan berpengaruh sangat nyata $(\mathrm{p}<0,01)$ terhadap total mikroba bubuk temu putih dalam kantung teh celup. Nilai rata- rata total mikroba bubuk temu putih dalam kantung teh celup dapat dilihat pada Tabel 2. 
Tabel 2. Total mikroba bubuk temu putih dalam kantung teh celup selama penyimpanan suhu ruang

\begin{tabular}{cccc}
\hline Sampel & $\begin{array}{c}\text { Total Mikroba } \\
(\text { Koloni/g) }\end{array}$ & $\begin{array}{c}\text { Standard SNI } \\
3836: 2013\end{array}$ & Keterangan \\
\hline 0 & $2,6 \times 10^{2}$ a & & Memenuhi syarat \\
7 & $4,3 \times 10^{2}$ a & $3 \times 10^{3}$ koloni/g & Memenuhi syarat \\
14 & $5 \times 10^{2} \quad$ a & Memenuhi syarat \\
21 & $1,73 \times 10^{3} \mathrm{~b}$ & Memenuhi syarat \\
28 & $2,76 \times 10^{3} \mathrm{~b}$ & Memenuhi syarat \\
\hline
\end{tabular}

Berdasarkan hasil pengujian nilai rata-rata total mikroba pada bubuk temu putih (Curcuma zedoaria (Berg) roscoe) dalam kantung teh celup berkisar antara 2,6 x $10^{2} \mathrm{koloni} / \mathrm{g}$ sampai dengan $2,76 \times 10^{3}$ koloni/g (Tabel 3). Persyaratan maksimal total mikroba pada syarat mutu kategori teh kering dalam kemasan sesuai SNI 3836:2013 adalah $3 \times 10^{3} \mathrm{koloni} / \mathrm{g}$ sehingga sampel bubuk temu putih dalam kantung teh celup memenuhi syarat mutu kategori teh kering dalam kemasan dengan nilai total mikroba yang tertinggi yaitu pada hari ke-28 sebesar $2,76 \times 10^{3} \mathrm{koloni} / \mathrm{g}$ dan nilai total mikroba yang terendah yaitu pada hari ke-0 sebesar 2,6 x 10² koloni/g.

Hasil perhitungan menunjukkan nilai total mikroba sampel bubuk temu putih dalam kantung teh celup semakin lama penyimpanannya akan mengalami peningkatan hal ini dapat disebabkan karena bubuk temu putih yang dikemas dalam kantung teh celup yang telah disimpan pada suhu ruang akan mudah menyerap air. Bubuk temu putih yang higroskopik bila disimpan dalam keadan terbuka pada ruangan menyerap lengas udara sehingga menjadi kempal basah atau mencair (Rahayu dan Setiowati,2010). Kenaikan kadar air pada produk cenderung meningkatkan nilai Aw produk. Pada nilai Aw yang cocok, mikroorganisme dapat bertumbuh dan berkembang biak (Wijaya, 2007). Perbedaan 2\% saja pada kadar air dapat membuat perbedaan besar dalam laju pertumbuhan mikroba saat penyimpanan dan laju kerusakan. Air sangat penting untuk kehidupan mikroba terutama karena mikroba hanya dapat mengambil makanan dari luar dalam bentuk larutan (holophytis). Semua mikroba tumbuh baik pada media yang basah dan udara yang lembab (Bala, 2017).

\section{Total AKK (Angka Kapang Khamir)}

Hasil analisis ragam menunjukkan bahwa lama simpan tidak berpengaruh nyata $(\mathrm{p}<0,05)$ terhadap AKK bubuk temu putih dalam kantung teh celup. Nilai rata- rata AKK bubuk temu putih dalam kantung teh celup dapat dilihat pada Tabel 3. 
Tabel 3. Angka kapang khamir (AKK) bubuk temu putih dalam kantung teh celup selama penyimpanan suhu ruang.

\begin{tabular}{|c|c|c|c|}
\hline Sampel & $\begin{array}{l}\text { Angka Kapang Khamir } \\
\text { (AKK) (Koloni/g) }\end{array}$ & $\begin{array}{c}\text { Standard SNI } \\
3836: 2013\end{array}$ & Keterangan \\
\hline 0 & $2,33 \times 10^{2} \mathrm{a}$ & & Memenuhi syarat \\
\hline 7 & $3,67 \times 10^{2} \quad a$ & & Memenuhi syarat \\
\hline 14 & $4,00 \times 10^{2} \quad \mathrm{a}$ & $5 \times 10^{2}$ koloni $/ g$ & Memenuhi syarat \\
\hline 21 & $3,33 \times 10^{2} \quad \mathrm{a}$ & & Memenuhi syarat \\
\hline 28 & $4,67 \times 10^{2} \quad a$ & & Memenuhi syarat \\
\hline
\end{tabular}

Berdasarkan hasil pengujian nilai rata-rata angka kapang khamir pada bubuk temu putih dalam kantung teh celup berkisar antara 2,33 x $10^{2}$ koloni/g sampai dengan 4,67 x $10^{2}$ koloni/g (Tabel 4). Persyaratan maksimal total mikroba pada syarat mutu kategori teh kering dalam kemasan sesuai SNI 3836:2013adalah $5 \times 10^{2}$ koloni/g sehingga sampel bubuk temu putih dalam kantung teh celup memenuhi syarat mutu kategori teh kering dalam kemasan persyaratan mutu minuman tradisional dengan nilai total mikroba yang tertinggi yaitu pada hari ke-28 sebesar 4,67 x $10^{2}$ koloni $/ g$ dan nilai total mikroba yang terendah yaitu pada hari ke-0 sebesar 2,33 x $10^{2}$ koloni/g.

Hasil perhitungan menunjukkan nilai angka kapang khamir sampel bubuk temu putih dalam kantung teh celup hampir sama dengan total mikroba, semakin lama penyimpanannya akan mengalami peningkatan hal ini dapat disebabkan karena bubuk temu putih yang dikemas dalam tea bag yang telah disimpan pada suhu ruang akan mudah menyerap air. Bila kadar air dalam bubuk terlalu tinggi, maka bubuk dapat berkapang karena air merupakan pelarut esensial yang dibutuhkan untuk perutumbuhan kapang khamir (Ali, 2005). Pada umumnya, kapang khamir tumbuh dengan baik di tempat yang lembab. Kapang khamir mampu menyesuaikan diri dengan lingkungannya. Suhu optimum pertumbahan kapang dan khamir yaitu $25-30^{\circ} \mathrm{C}$ sehingga penyimpanan suhu ruang akan meningkatkan pertumbuhan kapang khamir pada bubuk temu putih dalam kantung teh celup.

\section{Koliform dan Eschericia coli}

1) Uji Pendugaan Koliform

Analisis uji pendugaan Koliform dengan media Lactose Broth (LB) selama 48 jam lalu dilanjutkan dengan Uji Pendugaan Escherichia coli pada bubuk temu putih dalam kantung teh celup dihitung dengan perhitungan tabel Most Probable Number (MPN) atau APM yang menggunakan tiga seri tabung. Pengenceran seri dilakukan untuk mengurai kerapatan pertumbuhan koloni mikorba pada sampel yang akan diuji. Batas maksimum cemaran mikroba minuman tradisional sesuai SNI 3836:2013 untuk koliform adalah $<3,0$ koloni/g dan APM Escherica coli $<3 / \mathrm{g}$. 
Tabel 4. Hasil uji pendugaan koliform bubuk temu putih dalam kantung teh celup selama penyimpanan suhu ruang

\begin{tabular}{ccccc}
\hline Sampel & Seri A & Seri B & Seri C & Uji Pendugaan koliform APM (koloni/g) \\
\hline 0 & 0 & 0 & 0 & $<3,0$ \\
7 & 0 & 0 & 0 & $<3,0$ \\
14 & 0 & 0 & 0 & $<3,0$ \\
21 & 0 & 1 & 0 & $<3,0$ \\
28 & 2 & 1 & 1 & 20 \\
\hline
\end{tabular}

Analisis pendugaan E. coli dengan menggunakan Lactose Broth yang berisi tabung durham didapatkan hasil data uji pendugaan dengan menggunakan perhitungan tabel Most Probable Number (MPN) atau APM yang dapat dilihat pada Tabel 4. Kusuma (2009) menjelaskan proses fermentasi gula (laktosa) dalam media LB karena adanya bakteri koliform fekal yaitu Escherichia coli. Fermentasi gula dengan adanya energi yang dihasilkan bakteri akan menhasilkan asam piruvat dan asam asetat, kemudian muncul gelembung gas $\mathrm{CO}_{2}$ yang berada di dalam media. Namun uji pendugaan ini tidak dapat dijadikan acuan bahwa sampel yang terkontaminasi
Koliform terdapat E. coli karena pada uji pendugaan memungkinkan berkembangnya mikroba jenis lain. Oleh karena itu sampel dilanjutkan dengan uji penegasan untuk menentukan apakah sampel tersebut terkontaminasi E. coli yang patogen.

2) Uji Penegasan Escherichia coli

Hasil uji pendugaan kemudian dilanjutkan ke tahap uji penegasan yaitu dengan cara diambil 1 ml sampel dari tabung reaksi yang terdapat gelembung didalamnya kemudian diinokulasikan ke dalam media yang berisi EMBA. Uji dikatakan positif jika terdapat warna hijau metalik. Hasil uji penegasan E. coli dapat dilihat pada Tabel 5.

Tabel 5. Hasil uji penegasan $E$. coli bubuk temu putih dalam kantung teh celup selama penyimpanan suhu ruang

\begin{tabular}{cccc}
\hline Sampel & Escherichia coli $(\mathrm{cfu} / \mathrm{g})$ & Standard SNI 7388:2009 & Keterangan \\
\hline 0 & 0 & & Memenuhi Syarat \\
7 & 0 & $<3 / \mathrm{g}$ & Memenuhi Syarat \\
14 & 0 & Memenuhi Syarat \\
21 & 0 & Memenuhi Syarat \\
28 & 0 & Memenuhi Syarat \\
\hline
\end{tabular}

Berdasarkan hasil uji penegasan Escherichia coli pada bubuk temu putih dalam kantung teh celup memenuhi syarat mutu kategori teh kering dalam kemasan dengan nilai total Escherichia coli 0 (cfu/g). Hal ini menujukan bahwa sampel yang terkontaminasi Koliform tidak terdapat E. coli namun diduga mikroba jenis lain. Menurut penelitian Lobo et al. (2009), minyak atsiri yang telah diekstrak dari temu putih mampu menghambat pertumbuhan bakteri E. coli, Salmonella sp., S. aureus dan Bacillus cereus. 
senyawa ini diduga menghambat pertumbuhan $E$. coli pada produk bubuk temu putih.

\section{KESIMPULAN DAN SARAN}

\section{Kesimpulan}

1. Bubuk temu putih dalam kantung teh celup selama penyimpanan hari ke 0 hingga ke -28 mengalami perubahan yaitu terdapat peningkatan total mikroba, AKK, koliform dan kadar air, namun tidak terdapat pertumbuhan E. coli.

2. Bubuk temu putih dalam kantung teh celup selama penyimpanan hari ke-0 hingga ke-28 memenuhi syarat aman untuk dikonsumsi karena pertumbuhan mikroba berada di bawah batas maksimal SNI, namun kadar air pada hari ke-14 hingga ke 28 tidak memenuhi syarat SNI.

\section{Saran}

Bubuk temu putih dalam kantung teh celup sebaiknya disimpan dengan tempat yang tertutup pada suhu ruang untuk menghindari peningkatan kadar air sehingga mengurangi pertumbuhan mikroba.

\section{DAFTAR PUSTAKA}

Ali, A. (2005). Mikrobiologi Dasar (Jilid I). Makassar: State University of Makassar Press.

Cappuccino, J.C., dan N. Sherman. (1992)."Negative staining" Microbiology: a laboratory manual 3: 125-179.

Chen, Y.R., dan T.H. Tan. (1998). Inhibition of The c-jun n-terminal kinase (jnk) Signaling Pathway by Curcumin. Journal Oncogene. 17(2): 173-178.
Lobo R., K.S. Prabhu, dan A. Shirwaiker. (2009). Curcuma zedoaria Rosc. (White Turmeric): A Review of Its Chemical, Pharmacological and Ethnomedicinal Properties. J. Pharm. Pharmacol. 61: 13-21.

Handayani, Y. (2010). Kajian Pembuatan Teh Celup dengan Daun Pegagan (Centella asiatica L. Urban). Skripsi. Bogor: Fakultas Pertanian Institut Pertanian Bogor.

Pratiwi, S.T. (2008). Mikrobiologi Farmasi. Jakarta: Erlangga.

Radji, M. (2011). Mikrobiologi. Jakarta: Buku Kedokteran ECG.

Rahayu, W.S., D. Hartanti, dan M. Setiowati. (2010). Pengaruh Lama dan Tempat Penyimpanan Terhadap Kadar Kurkuminoid pada Sediaan Jamu Serbuk Merk "A" yang Mengandung Simplisia Rimpang Kunyit (Curcuma domestica, Val.). Jurnal Farmasi Indonesia (Pharmaceutical Journal of Indonesia). 7(2): 35-46.

Rahman, M.A., dan M. Yusuf, M. (2013). Zingiber salarkhanii (Zingiberaceae), A New Species from Bangladesh. Bangladesh Journal of Plant Taxonomy. 20(2): 239-242.

Shahzadi, N., M.S. Butt, S.U. Rehman, dan K. Sharif. (2005). Chemical Characteristics of Various Composite Flours. International J. of Agriculture and Biology. 7(1).

Sopandi, Tatang, dan Wardah. (2014). Mikrobiologi Pangan-Teori dan Praktik. Yogyakarta: Andi.

Sudarmadji, S.B. Haryono, dan Suhardi. (1997). Analisa Bahan Makanan dan Pertanian. Yogyakarta: Liberty.

Sumathi, S., G.T. Iswarya, B. Sivaprabha, B. Dharani, P.R. Radha, dan P. Padma. (2013). Comparative Study of Radical Scavenging Activity and Phytochemical Analysis of Fresh and Dry Rhizomes of Curcuma zedoaria. International Journal of Pharmaceutical Sciences and Research. 4(3): 1069-1073.

Wohlmuth, H. (2008). Phytochemistry and Pharmacology of Plants from the Ginger Family, Zingiberaceae. Tesis. Lismore, NSW, Australia: Southern Cross University.

Yuliasih, I., Sugiarto, dan Tedy. (2006). Pendugaan Umur Simpan Bubuk Jahe Merah (Zingiber officinale var. rubrum). Bogor: Departemen Teknologi Industri Pertanian, IPB. 